\title{
EVALUATING HOW THE TEMPERATURE CHANGES IN A SUNKEN SOLAR GREENHOUSE
}

\author{
Weiwei Cheng1, Junlin He${ }^{1 *}$, Zhonghua Liu ${ }^{2}$
}

\author{
${ }^{1 *}$ Corresponding author. College of Agricultural Engineering, Shanxi Agricultural University/ Taigu, China. \\ E-mail: hejunlin26@126.com. ORCID ID: https://orcid.org/0000-0001-8875-5966
}

\section{KEYWORDS}

Sunken solar greenhouse, Law of temperature variation, Wireless sensor, Near the membrane.

\begin{abstract}
An increasing amount of sunlight is available to sunken greenhouses located in northern China, but it remains unclear how the indoor temperature changes at different heights and at the north and south ends of the structure. To study how the temperature in a single indoor section, at multiple points, varies in a sunken solar greenhouse, 10 measurement lines were arranged in a section $30 \mathrm{~m}$ from the west wall. Each line was equipped with a corresponding WT-59 wireless sensor. Temperature and humidity data were collected from 8 March 2019 to 26 December 2019. The following results were obtained. (1) The indoor temperature variation in a day could be divided into four stages: from 0:00 to 7:30 $\mathrm{h}$, the temperature at all measurement points decreased linearly; from 7:30 to $14: 30 \mathrm{~h}$, the temperature at all measurement points increased curvilinearly; from 14:30 to 18:00, the temperature at all measurement points decreased curvilinearly; and from 18:30 to 24:00, the temperature at all measurements points decreased linearly. (2) The maximum temperature on sunny days in the greenhouse was higher than that on cloudy days and snowy days, but the maximum temperature on cloudy days and snowy days in the greenhouse occurred $3 \mathrm{~h}$ earlier than on sunny days. (3) The lowest average temperature of a sunken solar greenhouse over $3-6$ months was $7.5^{\circ} \mathrm{C}$, without heating. The research results provide theoretical and reference data on how the temperature changes in the interior of a solar greenhouse and inform about the three-dimensional planting height and ventilation times.
\end{abstract}

\section{INTRODUCTION}

A solar greenhouse is a high-efficiency, energy-saving gardening facility with Chinese characteristics. It is a kind of energy-efficient greenhouse structure and plays a significant role in the facility gardening industry in northern China (Bao et al., 2018 b; Chen, 2008; Zhang, 2015). Energy-saving solar greenhouse heat storage maximises the use of solar energy for indoor thermal energy through single or collaborative applications of structures, materials, and equipment (Zhang $\&$ Ping, 2015). Among the many wall insulation materials, a soil wall is favoured by farmers because of its excellent heat storage, available material selection, simple construction technology, and low cost; its application accounts for about $95 \%$ of all solar greenhouses (Huang et al., 2013). To reduce the influence of low-temperature soil, the area of a low-cut solar greenhouse is relatively large (Zhang et al., 2019). The main goal of the soil wall is to improve the minimum temperature of the sunken solar greenhouse at night, so it is crucial to study the temperature variation in different areas of the structure over time. However, there is limited research on sunken solar greenhouses with a soil wall in China and throughout the world (Zhang et al., 2012).

${ }^{1}$ College of Agricultural Engineering, Shanxi Agricultural University/ Taigu, China.

${ }^{2}$ College of Urban and Rural Construction, Shanxi Agricultural University/ Taigu, China.

Area Editor: Edilson Costa

Received in: 10-23-2020

Accepted in: 3-2-2021 
There has been some research on sunken solar greenhouses in China. Zhang et al. (2010) simulated the three-dimensional unsteady temperature field in a sunken earth wall greenhouse; the maximum relative error of the simulation was 5.9\%. Kang et al. (1992), Peng et al. (2014), and Wang et al. (2009), studied the thickness of an earth wall. Shi et al. (2016) studied the temperature variation law of a sunken solar greenhouse wall in Tai'an. They found that the temperature amplitude $0.7 \mathrm{~m}$ away from the inner surface of the wall tended to be stable. Huang et al. (2013) found that the wall's temperature amplitude after the thickness reached a particular value tends to be fixed, and the wall can be divided into a regenerative layer, a transition layer, and a cooling layer from inside to outside. Zhang et al. (2012) suggested that the construction parameters of the back wall of a sunken solar greenhouse in Hennan should be $2.5 \mathrm{~m}$ wide and 4.0 $m$ thick. Sun et al. (2009) monitored the marginal effect of soil temperature in a solar greenhouse and found that the soil temperature boundary point is different depending on the observation period. Zhang et al. (2019) used the theory of heat transfer science to analyse the relationship between the change rate of ground temperature and the heat release at different measurement points in the span direction. $\mathrm{Xu}$ et al. (2018) tested the temperature changes in a solar greenhouse under the exceptional climate of the desert hinterland and found that a solar greenhouse has a good heat preservation ability and low indoor relative humidity. These features can effectively ensure the growth and development of all kinds of fruit and vegetables; nevertheless, the heat storage capacity is insufficient.

All the above-mentioned studies have led to improvements in the thickness of the soil wall of a solar greenhouse, but researchers have not studied the heat dissipation law within a solar greenhouse over time. The existing solar greenhouse structure dissipates too much heat, which leads to freeze damage (Zhang et al., 2015). Heat accumulators such as indoor walls and soil are passive heat storage; the heat storage depth of the passive heat storage wall and the land is limited. The unused indoor surplus heat will still be released outside with cold air penetration, heat transfer in the ground, ventilation, etc. (Bao et al., 2018 a). Therefore, it is important to have a comprehensive understanding of wall heat release in a sunken solar greenhouse and how heat dissipation occurs in the structure. This information is crucial for temperature control in a sunken solar greenhouse.

\section{MATERIAL AND METHODS}

\section{Experimental greenhouse}

The experiment was carried out from 8 March 2019 to 26 December 2019 at the base of Juxin Agricultural Science and Technology Development Co, Ltd, Taigu County, Shanxi Province, China $\left(112.55^{\circ} \mathrm{E}, 37.42^{\circ} \mathrm{N}\right)$. The experimental greenhouse is a sunken three-dimensional planting solar greenhouse, as shown in Figure 1. The greenhouse faces south with a northern sunken earth wall; it is $108 \mathrm{~m}$ long and $12 \mathrm{~m}$ wide. The sunken depth of the south side of the sunken greenhouse is $1.2 \mathrm{~m}$, the width of the south crossing is $1.1 \mathrm{~m}$, and the width of the north crossing is $1.2 \mathrm{~m}$. The sunken solar greenhouse rear wall outside height is $4.3 \mathrm{~m}$ and the ridge height is $4.8 \mathrm{~m}$. The width under the fence is $6 \mathrm{~m}$ and the top diameter is $2 \mathrm{~m}$. The main bearing force skeleton adopts an elliptical steel pipe; the skeleton spacing is $1.8 \mathrm{~m}$, and the transparent covering material is plastic film. The greenhouse has an A-type cultivation frame, and the vertical spacing of the adjacent layers are $0.5 \mathrm{~m}$. The 'red face' strawberry varieties were planted on 31 August 2019, with a plant spacing of $0.15 \mathrm{~m}$.

\section{Testing instruments}

A HT59-LI-A1 wireless temperature and humidity collector and WG59 net were used. This device collected the internal temperature and relative humidity in the greenhouse. The wireless temperature and humidity collector transmits the collected temperature and humidity to the WG59 gateway through the signal. The WG59 portal receives the data information using a private Internet network. The data are transferred to the cloud server and are then accessible with a mobile phone or a computer. The temperature measurement range is from $-40^{\circ} \mathrm{C}$ to approximately $85^{\circ} \mathrm{C}$; the accuracy is $\pm 0.2^{\circ} \mathrm{C}\left(0-65^{\circ} \mathrm{C}\right)$ and $\pm 1^{\circ} \mathrm{C}$ (all other temperatures). Measurements were made and transmitted continuously every $5 \mathrm{~min}$ during the experimental period.

\section{Testing methods}

The test position was $30 \mathrm{~m}$ from the west wall body; 10 locations were selected along this section. At each location, S-type hooks were hung $300 \mathrm{~mm}$ above the ground to carry a wire rope with the wireless temperature and humidity collection instrument. The layout diagram of each line is shown in Figure 1 (wire rope length only, not including the range of the S-type hooks), and the top temperature measurement point number of each line is 1 (1-1 represents the measurement point position at the top of line 1), which is sorted from top to bottom. The vertical spacing of adjacent measurement points is $0.3 \mathrm{~m}$. The spacing of adjoining measurement points is shown in Table 1. The No. 1 line is located on the subsidence surface, and the No. 3 line is in the south corridor area. The No. 4 line is located at the end of the strawberry planting area. The No. 10 line is located at the interior surface of the north wall, which has an inclination of $55^{\circ}$.

The greenhouse automatically determines the timing of the curtain release according to the weather conditions and when the vent open. Up to mid-April, when the weather conditions are snowy or rainy, the vent is in an unventilated state to prevent rain water from entering the shed. After late April, when the wind reaches level 5, the curtain cotton is pressed on the upper vent to prevent damage to the shed; for other periods, the top vent is in a ventilated state. 


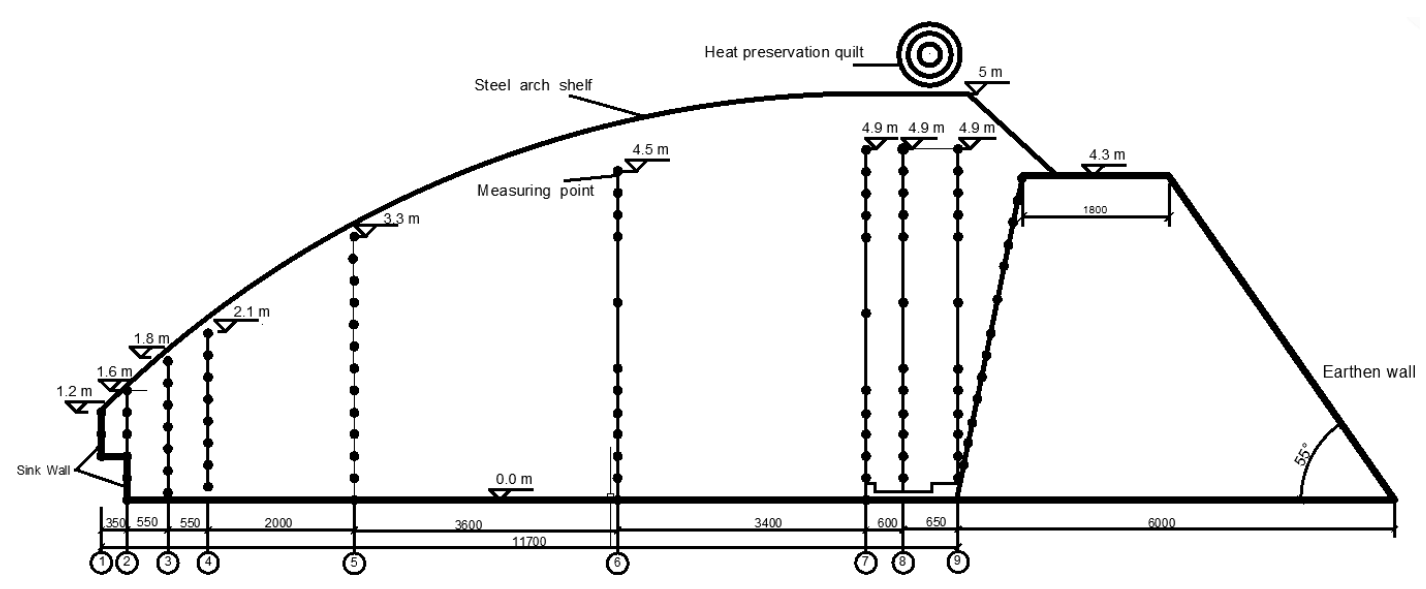

FIGURE 1. Line layout.

TABLE 1. Measurement point spacing diagram. (unites: $\mathrm{m}$ )

\begin{tabular}{|c|c|c|c|c|c|c|c|c|c|c|c|}
\hline & \multirow[b]{2}{*}{ Measurement point code } & \multicolumn{10}{|c|}{ Line number } \\
\hline & & 1 & 2 & 3 & 4 & 5 & 6 & 7 & 8 & 9 & 10 \\
\hline 1 & & 1.2 & 1.6 & 1.8 & 2.1 & 3.3 & 4.5 & 4.9 & 4.9 & 4.9 & 4.3 \\
\hline 2 & & 0.9 & 1.3 & 1.5 & 1.8 & 3 & 4.2 & 4.6 & 4.6 & 4.6 & 4 \\
\hline 3 & & 0.6 & 1 & 1.2 & 1.5 & 2.7 & 3.9 & 4.3 & 4.3 & 4.3 & 3.7 \\
\hline 4 & & & 0.7 & 0.9 & 1.2 & 2.4 & 3.6 & 4 & 4 & 4 & 3.4 \\
\hline 5 & & & 0.4 & 0.6 & 0.9 & 2.1 & 2.7 & 3.7 & 3.7 & 3.7 & 3.1 \\
\hline 6 & & & 0 & 0.3 & 0.6 & 1.8 & 1.8 & 2.7 & 2.7 & 2.7 & 2.5 \\
\hline 7 & & & & 0 & 0.3 & 1.5 & 1.5 & 1.5 & 1.7 & 1.7 & 1.9 \\
\hline 8 & & & & & 0.1 & 1.2 & 1.2 & 1.2 & 1.4 & 1.4 & 1.6 \\
\hline 9 & & & & & & 0.9 & 0.9 & 0.9 & 1.1 & 1.1 & 1.3 \\
\hline 10 & & & & & & 0.6 & 0.6 & 0.6 & 0.8 & 0.8 & 1.0 \\
\hline 11 & & & & & & 0.3 & 0.3 & 0.3 & 0.5 & 0.5 & 0.7 \\
\hline 12 & & & & & & 0 & 0 & 0 & 0.3 & 0.2 & 0.4 \\
\hline
\end{tabular}

\section{Theoretical basis}

The phenomenon of heat transfer generated by the flow of a fluid on a solid surface is called convective heat transfer. The heat exchange formula (Xu et al., 2018) between greenhouse air and surface is:

$$
\Phi=h A\left(T_{g}-T_{f}\right)
$$

In Equation (1), heat flux $h$ is the convection heat transfer coefficient, namely $\mathrm{W} /\left(m^{2} \bullet k\right)$; A is the greenhouse floor area in $\mathrm{m}^{2} ; T_{g}$ is the ground temperature or the rear wall surface temperature in $\mathrm{K}$; and $T_{\mathrm{f}}$ is the ground air temperature or the rear wall air temperature in $\mathrm{K}$. As can be seen from [eq. (1)], for exothermic soil, $T_{\mathrm{f}}$ is the fixed value, and the higher $T_{g}$ is at night, the more heat is released to the soil.

The night greenhouse air and outdoor conduction heat transfer and solar greenhouse internal and outdoor conduction heat is calculated with [eq. (2)]:

$$
Q=\mu_{j} A_{j}\left(t_{1}-t_{2}\right)
$$

Where:

$Q$ indicates conduction heat loss;

$\mu_{j} \quad$ indicates maintenance of heat transfer coefficient of structure, namely $\mathrm{W} /\left(m^{2} \bullet k\right)$;

$t_{1}$ is the temperature inside the solar greenhouse (beneath the plastic film) in ${ }^{\circ} \mathrm{C}$, and

$t_{2}$ is the outdoor temperature in ${ }^{\circ} \mathrm{C}$.

\section{Data processing methods}

Origin8.5 was used for data analysis and fabrication of two-dimensional charts. SPSS 25.0 (IBM Inc., Armonk, NY, USA) was used for variance analysis and multiple comparisons of the temperature difference.

\section{RESULTS AND DISCUSSION}

Temperature variation in the solar light greenhouse 

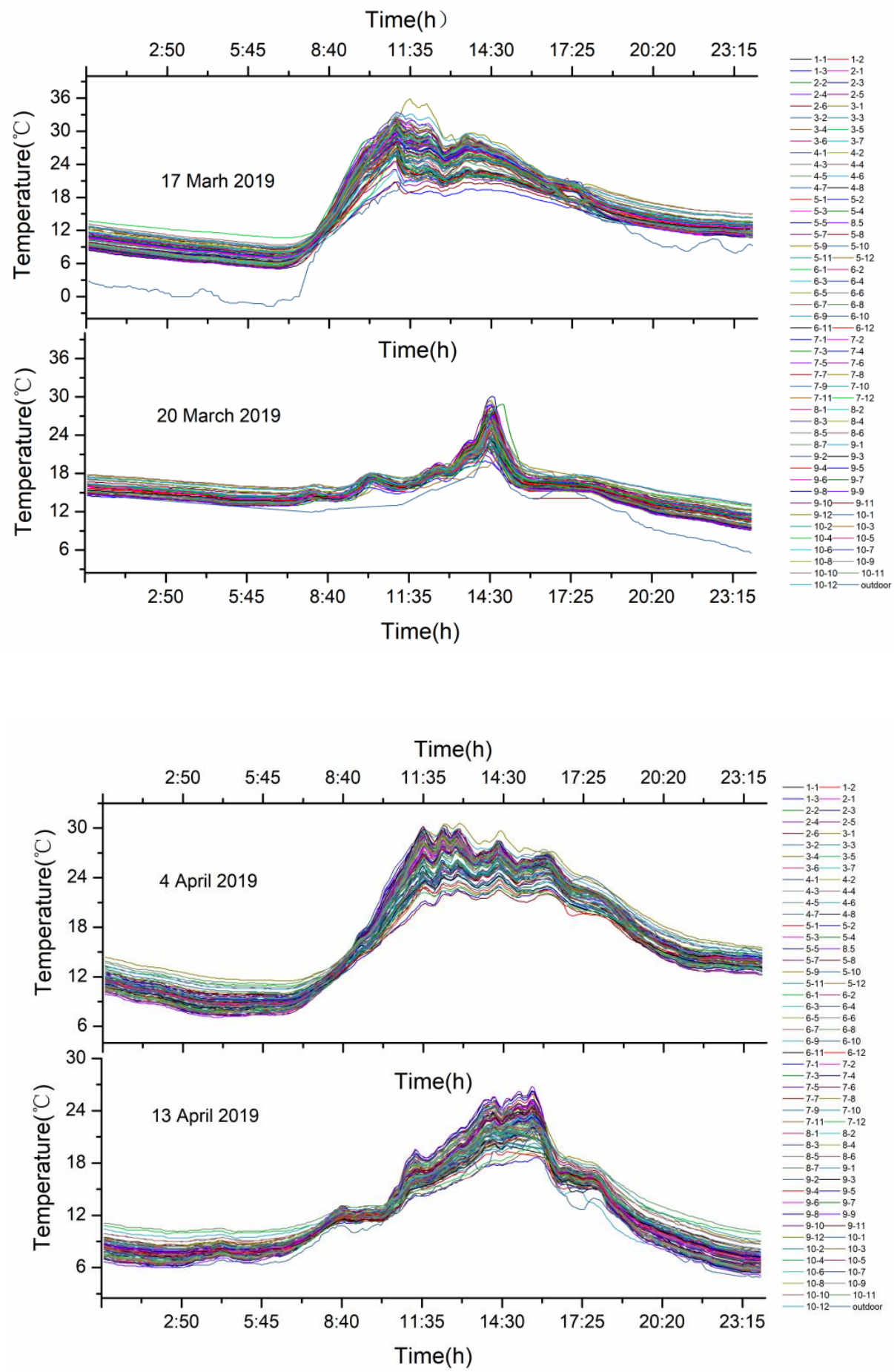


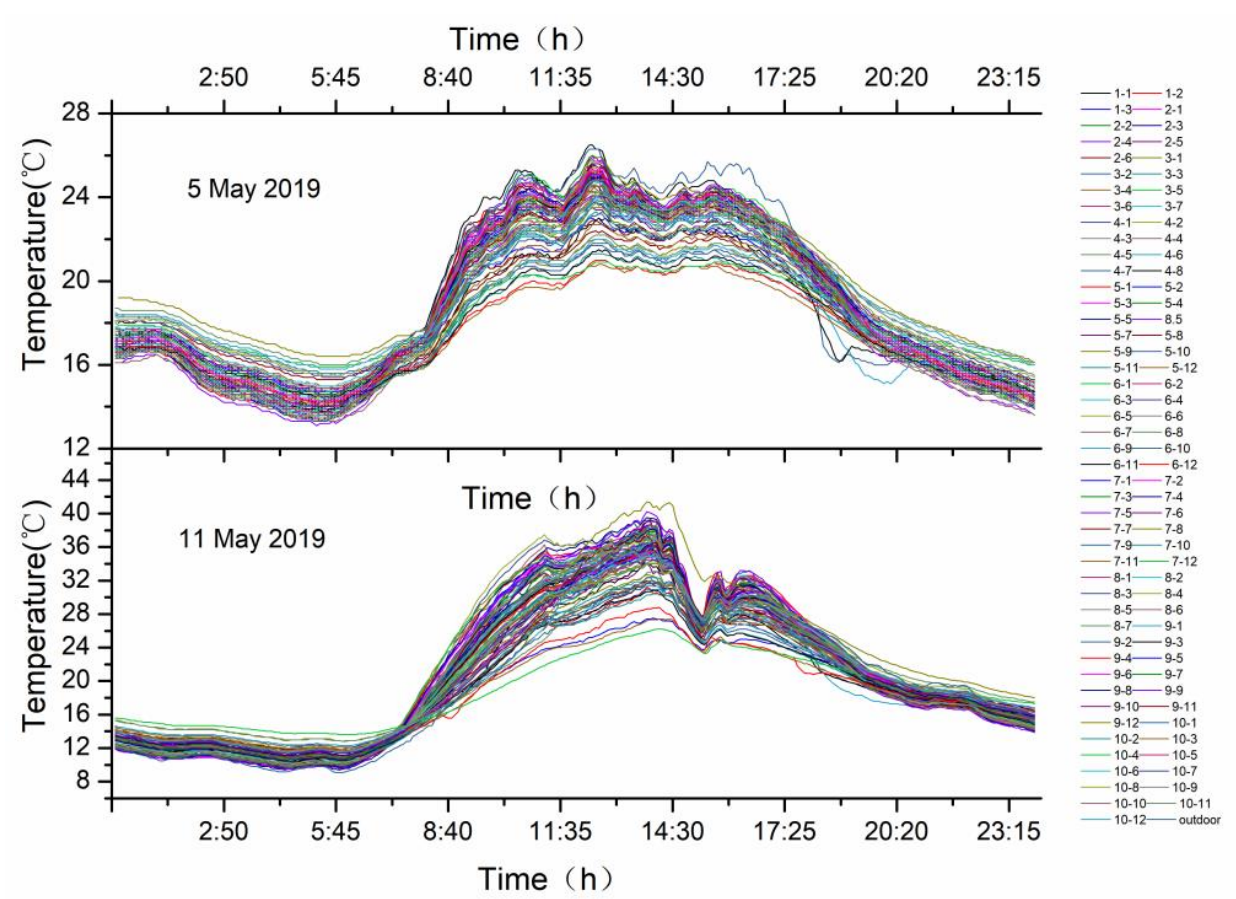

FIGURE 2. Temperature variation of each measurement point in the solar greenhouse. Note: 17 March 2019 was sunny, 20 March 2019 was cloudy, 4 April 2019 was sunny, 13 April 2019 had sleet, 5 May 2019 was sunny, and 11 May 2019 , cloudy.

Figure 2 shows the temperature change curves for inside and outside the sunken greenhouse on certain days. The temperature of each measurement point in the cross-section of the solar greenhouse varied with time: the indoor temperature increased or decreased as the outdoor temperature changed. The nighttime period (19:00 to 7:00 h) showed a linear pattern. For the daytime period (7:00 to 19:00), the temperature curve presented a parabola that opens downward, with the highest point between 14:00 and 14:30. In March, the indoor temperature was $<10^{\circ} \mathrm{C}$ when the greenhouse was covered and the vent was closed. The maximum and minimum temperatures and heating rate of the shed on sunny days was higher than on cloudy days or days with rain and/or snow weather. The temperature loss is caused by the heat exchange near the shed membrane, and the difference between the temperature compensation value and the temperature loss value changed linearly with time. During the day, the temperature increase is mainly due to solar radiation and respiration. The temperature loss is primarily caused by heat absorption, soil heat absorption, and transpiration of the north wall.

\section{Variation of temperature near the membrane}

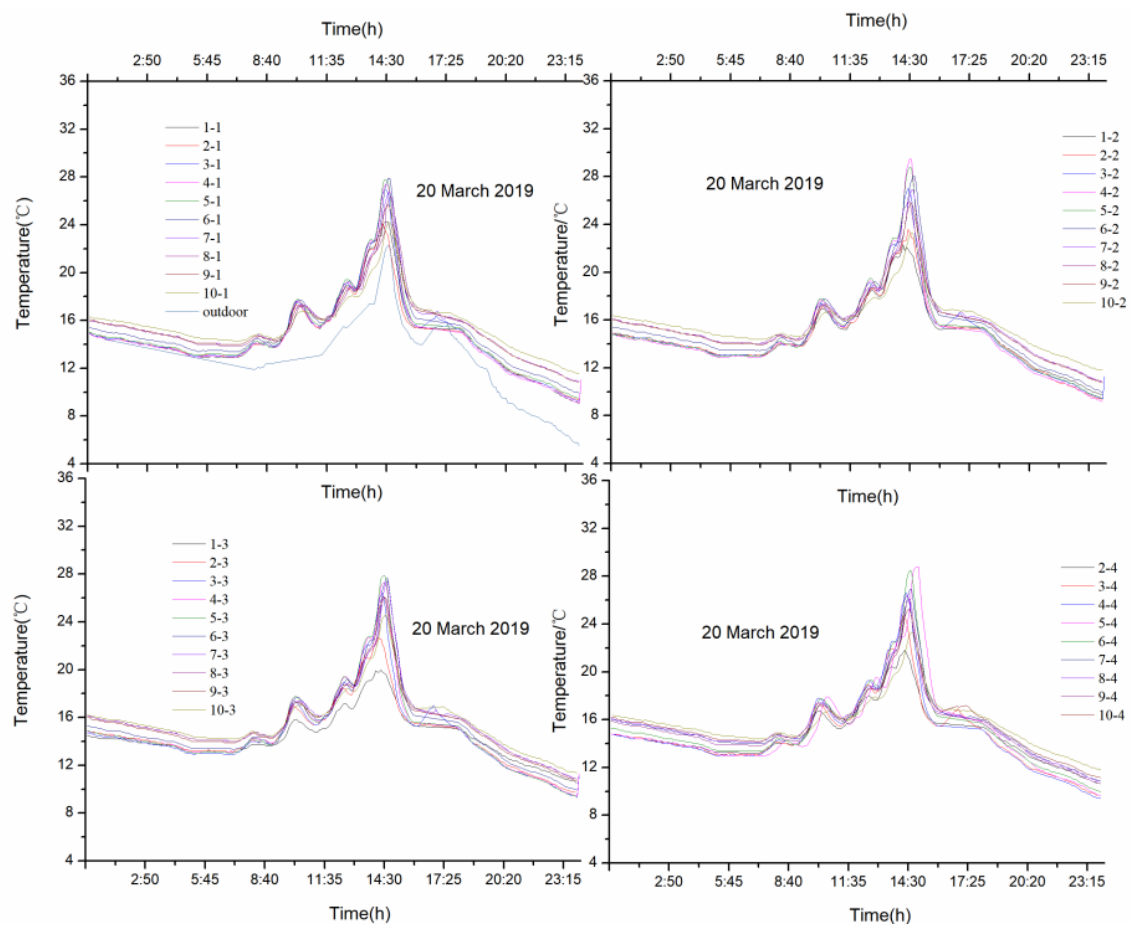

FIGURE 3. Temperature curves near the film on 20 March 2019. 
Figure 3 shows the temperature curves for the area near the shed film (four measurement points) over time, showing the corresponding adjustment of the temperature near the shed film with sunrise at 07:12 $\mathrm{h}$ and sunset at 18:40 $\mathrm{h}$. The indoor temperature began to rise to a maximum peak of $32-35^{\circ} \mathrm{C}$, at a rate of $4.58^{\circ} \mathrm{C} / \mathrm{h}$, and gradually began to decrease after $14: 30 \mathrm{~h}$, to $12-15^{\circ} \mathrm{C}$ at $18: 40 \mathrm{~h}$, at a speed of $4.80^{\circ} \mathrm{C} / \mathrm{h}$. From $18: 40$ to $7: 12 \mathrm{~h}-$ that is to say, during the night and into the early hours of the morning - the temperature was maintained at $5-10^{\circ} \mathrm{C}$. The temperature near the shed film changed regularly with the sunrise and sunset, and the temperature increase rate near the shed film caused by sunrise and sunset was the same. The temperature near the film at night remained relatively constant.

\section{Temperature variation in different weather conditions}

On a sunny day, the temperature of the greenhouse was higher than on overcast and snowy days. However, the peak temperature on overcast and snowy days occurred $3 \mathrm{~h}$ earlier than on sunny days. This difference is because the temperature change in the greenhouse is related to the intensity of solar radiation and the ambient temperature outside the greenhouse. Under the closed conditions, solar radiation can be converted into heat energy, which can increase the temperature in the greenhouse. The solar radiation obtained in the greenhouse on a sunny day is intense, and the temperature can rise quickly. By contrast, when solar radiation is weak, the temperature rises slowly. The temperature difference between the inside and outside of the greenhouse on a sunny day is more prominent than on a cloudy day or at night, so the temperature decreases at night on a cloudy day. Due to the low temperature outside the greenhouse, and the lack of external sources of heat, the temperature in the greenhouse rises slowly and falls rapidly.

The temperature difference can affect plant height, leaf area, and sex differentiation. Greater differences can promote the differentiation of female flowers, so if there is continuous rain and snow during flowering, it is necessary to warm up the greenhouse during the day to improve plant fruit setting. The lowest indoor average temperature in a sunken greenhouse was $7.5^{\circ} \mathrm{C}$, without heating; hence, suitable plant species need be selected that can tolerate the minimum average temperature in the greenhouse. Besides, the minimum guaranteed temperature is the minimum temperature that the solar greenhouse of the established structure can maintain in a particular place, and this index is of great significance for selecting suitable crops and regulating the environment reasonably.

The total solar radiation transmittance in the sun-sinking solar greenhouse is $25 \%-80 \%$. Therefore, a light-free film with high transmittance, strong weather resistance, and sound insulation should be selected to ensure the cold temperature and illumination environment in the greenhouse, and the light-bar in the greenhouse can be improved by hanging reflective film. The total solar radiation inside and outside the sunken solar greenhouse is positively correlated, and the diurnal variation of the total solar radiation in the greenhouse is parabolic. Hence, the average total solar radiation in the greenhouse can be estimated according to the total solar radiation outside the greenhouse. Furthermore, light can be supplemented according to needs to provide a theoretical reference for rational light management of the greenhouse. A sunken solar greenhouse also has a façade along the south edge. This design makes the distribution of the total solar radiation in the inner and lower layers in the horizontal and vertical directions of the north and south more complicated in the spatial distribution than in ordinary greenhouse. Thus, it is necessary to plant crops according to their characteristics and form a reasonable population structure to make full use of the inner space of the greenhouse.

\section{CONCLUSIONS}

The temperature in a sunken solar greenhouse is distributed very ununiformly in the same cross section at the same time. In March in the morning, the difference in the lowest temperature at different points in the greenhouse at the same time was greater than $9^{\circ} \mathrm{C}$. In May, this difference was greater than $14^{\circ} \mathrm{C}$. Referring to the lowest temperature, researchers can take corresponding measures to avoid frost, and shading methods such as reference peak can be taken to avoid high temperature damage. To explore the distribution of temperature in the three-dimensional space of a sunken solar greenhouse, the indoor temperature distribution can be more accurately studied to reduce the temperature difference inside the greenhouse and ensure the uniformity of indoor fruits. Therefore, the study on the two-dimensional and three-dimensional temperature distribution law of a sunken solar greenhouse can provide corresponding reference data that allows automating agricultural control.

\section{REFERENCES}

Bao EC, Cao YF, Zou ZR, Shen TT, Zhang Y (2018 a)

Research progress of thermal storage technology in energy-saving solar greenhouse. Transactions of the Chinese Society of Agricultural Engineering 34(6):1-14.

Bao EC, Zou ZR, Zhang Y (2018 b) CFD simulation of heat transfer in back-wall of active thermal-storage solar greenhouse with different airflow directions. Transactions of the Chinese Society of Agricultural Engineering 34(22):169-177.

Chen QY (2008) Progress of practice and theory in sunlight greenhouse. Journal of Shanghai Jiaotong University: Agricultural Science 26(5):343-350.

Huang X, Wang XF, Wei M, Hou JL,Liu FS,Li QM, Yang FJ,Shi QH (2013) Variation patterns of soil wall temperature and heat flux in sunken solar greenhouse. Chinese Journal of Applied Ecology 24(6):1669-1676. Kang SH, Fang SQ, Dai YD, Wei KJ,Chen RS,Zheng

HS(1992) Study on wall material and structure of energy solar performance optimization of the solar saving solar greenhouse. Chinese Vegetables 6:1-5. 
Peng DL, Yang QC, Wei LL,Zhang Y,Fang H (2014) Measurement and heatflux analysis on north earthen wall in Chinese solar greenhouse. Chinese Agrometeorology 35(2):168-173.

Shi YL, Wang XF, Wei M, Li QM, Liu FS, Hou JL (2016) Temperature variation, heat storage and heat release characteristics of soil wall in solar greenhouse. Transactions of the Chinese Society of Agricultural Engineering 32(22):214-221.

Sun ZQ, Sun L, Wang Q, Li SL(2009) Marginal effect of the soil temperature environment in greenhouse.

Transactions of the Chinese Society of Agricultural Engineering 25(5):150-155.

Xu HJ, Li YR, Cui YM, Jiang WJ, Zou ZR (2018) Thermal performance test and analysis of solar greenhouse in hinterland of Hetian desert, Xinjiang. Transactions of the Chinese Society of Agricultural Engineering 34(Supp.): $60-65$.

Wang XD, Ma CW, Wu LT, Zhang L (2009) Characteristic research and greenhouse wall. Xinjiang Agricultural Sciences 46(5):1016-1021 (in Chinese with an English abstract).
Zhang CK, Wei M, Liu FS, Xu PL, Li Y (2019) Soil unsteady thermal conduction process in a divot solar greenhouse at night. Journal of China Agricultural University 24(1):108-118.

Zhang JZ, Chang HP (2015) Heat Transmission Science. Beijing, Science Press:60-61, 2ed.

Zhang LH, Zhang F, Liu S,Xu L (2010)Three-dimensional non-steady-state simulation of sunken cob wall greenhouse indoor temperature field. ActaEnergiae Solaris Sinica 31(8):965-971 (in Chinese with an English abstract).

Zhang Y, Gao WB, Zou ZR (2015) Performance experiment and CFD simulation of heat exchange in solar greenhouse with active thermal storage back-wall. Transactions of the Chinese Society of Agricultural Engineering 31(5):203-211.

Zhang ZH (2015) Application and development of agricultural plastic technology in horticultural industry. China Vegetables 7:1-5.

Zhang ZL, Wang SQ, Liu ZH, Sun ZQ (2012) Experiment and analysis on thermal characteristics of cob wall in sunken solar greenhouse. Transactions of the Chinese Society of Agricultural 28(12):208-215 (in Chinese with an English abstract). 